This is an Accepted Manuscript of an article published by Taylor \& Francis in JOURNAL OF PEACE EDUCATION on September 2014 (Volume 11, Issue 1, ) available online: http://www.tandfonline.com/ Article DOI: 10.1080/17400201.2013.794335

\title{
Implementing restorative justice practice in schools: What pedagogy reveals
}

\begin{abstract}
:
In the ongoing pursuit for creating safe, nurturing and relational school cultures, educators continue to turn to restorative justice (rj) principles and practice. Predominantly, schools begin to engage with rj in an effort to address harm done, causing its discourse to be situated in literature tied to classroom management and behaviour. However, in this location, the effectiveness of rj can be limited because the power relationships underlying the original punitive, managerial structures maintain their grip. Drawing on a qualitative study that examines the experiences of educators committed to implementing rj principles, this article explores how placing $\mathrm{rj}$ in the context of engaged, productive pedagogies better nurtures the hoped for relational, peaceful school culture.
\end{abstract}

Keywords: restorative justice; pedagogy; engaged pedagogies; productive pedagogies; classroom management; behaviour; safe and caring schools

Schools across the globe are turning to restorative justice (rj) practices in hopes of developing safe and caring school cultures that will effectively support the academic purpose of schooling. What sets rj apart from other safe-school/anti-bullying initiatives is its philosophical foundation that emphasizes the inherent worth and well-being of all people (Bianchi 1994; Vaandering 2011; Zehr 2005), the belief that humans are “profoundly relational” (Pranis 2007) and its goal to replace punitive, managerial structures of schooling with those that emphasize the building and repairing of relationships (Hopkins 2004; Morrison 2007).

According to research that explores the effectiveness of other safe-school/antibullying initiatives, many approaches demonstrate limited success because they emphasize the individual, rather than the relationship between those experiencing conflict 
or the system of which they are a part (Jones 2004; Lindstrom 2007; Morrison 2005), or because they are rooted in the same power relationships underlying the punitive approaches the new ones are seeking to replace (Morrison 2005).

Restorative justice, with its philosophical foundation, holds potential for escaping this limitation of success as it relies on a relationship-based, dialogic framework that contrasts with the more common hierarchical, power-based structure. However, amongst the studies and reports that find rj is successfully making inroads and is responsible for significant changes in schools, several recent studies (McClutsky 2008; Reistenberg 2011; Vaandering 2009) amplify the early concerns of Morris (1998), who stated that rj is poised for being co-opted by the power structures that underlie the punitive managerial structures of society.

According to McClutsky et al. (2008), the tendency to focus on behaviour reveals a default position that is difficult to change. In the conclusion to their comprehensive study of a pilot project in Scotland, they state that "the central challenge of restorative practices, we would suggest, lies ... in its contrast with the habitus of schools; with the 'taken for granted' structures and systems of discipline and control in schools" (413). This default position is evident in training content, supporting resources, resulting practice, as well as research reports indicating that despite the relational foundation of $\mathrm{rj}$, educators and schools continue to emphasize its value as a strategy for changing student behaviour (Porter 2007; Morrison 2007).

Harber and Sakade (2009), in their study of peace education programs and 'normal' schooling in England, shed light on the 'taken-for-granted' structures and 
systems to which McClutsky refers. They identify a growing, international literature that includes the official recognition by the UN of the role of schooling in sustaining overt forms of violence, and reveals schools as reproducing and perpetrating violence (Pinherio 2006 in Harber and Sakade 2009). By drawing on Green (1990), who traces the historical roots of the nature of schooling globally, they identify that authoritarian, hierarchical structures of schooling were implemented to inculcate habits of obedience and conformity.

The task of public schooling was not so much to develop new skills for the industrial sector as to inculcate habits of conformity, discipline and morality that would counter the widespread problems of social disorder (59).

In spite of efforts over time to encourage education for critical consciousness, individual liberation, and participatory democracy, Harber and Sakade identify that social reproduction, and education for control and compliance, are "deeply embedded in schooling and highly resistant to change" (173).

This dominant context is the one rj, with its contrasting philosophy, has been seeking to enter. This article reports on a study done in Ontario, Canada in which the impact of rj training on teacher pedagogy was examined. Findings reveal how rj, situated in the discourse of behaviour and classroom management, inadvertently reinforces an agenda of compliance and control rather than its intended purpose of building relational, interconnected and interdependent school cultures. However, rj situated in the discourse of engaged (hooks 1994) and productive pedagogies (Hayes, Mills, Christie and Lingard 2006), which identify well-being and connectedness as key components of effective teaching and learning, provides a new lens for understanding how rj can experience 
continued expansion in schools. By examining pedagogy, which in its most fundamental form is defined as "any conscious activity by one person designed to enhance the learning of another" (Watkins and Mortimore 1999), attention is shifted away from student (mis)behaviour and classroom management to teaching and learning.

The article is organized into four main parts. The first sets out the background that includes an overview of rj in schools, the research framework, and methodology. The second presents an overview of the study's findings followed by a close examination of two of the participants to reveal the contrasting impact of a shared rj training experience. The third discusses the significance of the findings for the field of rj in education. Finally, the need for further research is identified.

\section{Background:}

\section{What is restorative justice in a school context?}

Restorative justice has been interpreted in a variety of ways in school contexts. For many schools, rj begins as a response to specific, harmful student behaviour, and attempts to grow into an approach that engages all students in an environment that encourages respectful, caring interaction. Most proponents of rj agree that it is rooted in indigenous and spiritual traditions that emphasize the interconnected nature of relationships within a community seeking to honour and promote the well-being of all its members (Amstutz and Mullet 2005; Hadley 2001; Morrison 2007; Pranis, Stuart, and Wedge 2003; Zehr 2005; Lockhart and Zammit 2005). The following key principles are represented in much of the school-based rj literature:

- Restorative justice addresses harm done, not rules broken; 
- Restorative justice promotes healthy, caring communication and fosters nurturing relationships;

- Restorative justice facilitates dialogue for those affected by harm, those responsible for causing harm, and their supporting community members in order to expose and then address the needs of all;

Variations appear when school policy statements, training content, and educator interpretations build on these to address a particular context. The actual expression of rj can be located along the continuum of replacing punitive, managerial structures of schooling with those that emphasize the building and repairing of relationships (Hopkins 2004). On the one end, rj supplements or parallels codes of conduct, and is employed to address serious incidents of harm only. At the other end, $\mathrm{rj}$ is understood more fully in terms of a restorative, responsive framework that includes building, maintaining and repairing relationships (Bickmore 2011; Hopkins 2011; Morrison 2007; Reistenburg 2011; Vaandering 2009)

\section{The research framework}

Several theories create the framework that supports the study's focus on pedagogy in order to understand the tendency for schools and educators to focus on behaviour when implementing rj.

Critical theory is used to identify and understand the theory/practice gap by examining the role of power in practice. In considering "how what is, has come to be, whose interests are served by particular institutional arrangements, and where our own frames of reference come from" (Kincheloe and McLaren 2000, 303), hidden 
assumptions are exposed within the practice of rj. Specifically, the insights of Freire (2005) and hooks $(1994,2003)$ are used as they offer a deep understanding of antioppressive, dialogic education and its capacity for transformation that leads to a more nuanced understanding of power relations in educational communities. hooks, building on Freire's concepts of humanization, conscientization and praxis, further identifies how power is embedded in pedagogy, and thus has the capacity to either undermine or support change. Conflict transformation theory (Lederach 2003) supports this critical framework by recognizing the need to situate the individual within one's social context. This theory identifies how transformation becomes possible only when conflict is understood in the context of its cause. Both of these theories are especially well-suited to this study, as the end purpose of such a critique is to produce action that leads to the overall improvement of the human condition (Kincheloe and McLaren 2000). This ties into the goal of rj as well as the goal of pedagogy as a means for enhancing the learning of another.

Engaged pedagogy provides a framework that recognizes how curriculum content and teacher approach can nurture or diminish the well-being of students. Learning contributes to the development of the person as a whole being, not only to intellectual growth. Engaged pedagogy is particularly well-suited for unpacking how rj practices in schools can be influenced by, or reinforce, systems of domination (hooks 1994).

Productive pedagogies provide a framework that highlights how effective teaching comes from incorporating four key elements: intellectual quality, connectedness, supportive classroom environment, and valuing and working with difference. This approach, arising from a large study in Australian schools, identifies these practices as necessary in order to have an impact on academic and social outcomes of all students, 
regardless of background (Lingard, Hayes and Mills 2003). It is also a reminder of the need to address the current pitfall of "widely employed models of discipline [being] promoted and disseminated with little reference to the broader curriculum context" (Field 2002,3 ) and the reality that the vast majority of teachers continue to ignore the connection. This connection between teaching practice and social outcomes is of particular significance as rj seeks to establish relational school cultures.

Much of the research examining rj in education highlights its effectiveness in terms of changes in numbers of expulsions, suspensions, and office referrals (Porter 2007; Morrison 2007), reinforcing the view that rj has little bearing on the academic component of schooling and thereby is not a philosophy but a strategy. When teachers' voices are heard within the framework provided by critical theory, conflict transformation theory, engaged, and productive pedagogies, the current understanding of rj for building safe school communities comes closer to its philosophical intent of developing caring, relationship-based cultures that contribute to education as the practice of freedom and a location of healing (hooks 2003) — a view distinct from the historical and contemporary imperatives that encourage schools to be "dehumanizing institutions that stress cognitive forms of knowledge over the affective, and that play down important inter-personal skills" (Harber and Sakade 2009, 184).

\section{The research methodology}

The methodological approach to this investigation is guided by rj principles to ensure that research practice would honour and nurture relationships (Toews and Zehr 
2003). To that end, creating safe spaces for those involved to listen and respond to each other's stories, is vital. In this context, a two-fold methodology developed.

First, case study allows for a gathering of comprehensive, systematic, and indepth information about rj in action (Patton 2002, 447), so that further knowledge is produced to illustrate, support, challenge and expand initial theories of $r j$ in education. Through purposeful sampling, information-rich cases, built on perspectives and experiences of specific individuals implementing rj practices are produced, rather than empirical generalizations. Thus, details regarding implementation, implications, and consequences of rj practices emerge to create more effective practice (Patton, 2002, p. 203). Second, the centrality of narrative to the rj philosophy itself, gives credence to its use for this inquiry as does the fact that teacher knowledge is a narrative construction composed in each teacher's life and made visible in practice (Clandinin, Huber, Murphy, Orr, Pearce, et al. 2006). This study combines narrative with critical inquiry, and is thereby strengthened through the use of interpretive strategies to reveal and then explain how the participants' stories may be "constrained by, and or strain against, the mediating aspects of their culture" (Chase 2005, 668). Lather (1986) identifies that participants and readers of such a study will critique as well as question the "taken-for-granted beliefs and the authority that culture has over us" (49). This is important as the intent of this study is to examine how rj is being enacted in schools accustomed to hierarchical, authoritarian governance structures.

\section{Data sources and evidence}


The data used for this paper comes from the more comprehensive study that investigates the implementation and sustainability of rj in Ontario school environments using the questions: What does rj look like, sound like and feel like in schools? What do the voices of teachers and principals reveal about the practice of rj and its philosophy? How can this knowledge contribute to the effective implementation and sustainability of restorative practices in school communities in such a way that its transformative potential can be experienced? (Vaandering 2009).

Two schools were selected for the study and data was gathered using on-site observation, policy analysis, and semi-structured interviews with administrators and educators. It is significant that each school is located in a different school board for three reasons. First, they were the only two boards in the province at the time that had adopted rj practice for all of their schools. Second, each had been implementing rj for a three-year period. Finally, each had a different training approach and implementation strategy that might contribute to a broader understanding of how rj was being enacted.

The two schools selected were of similar size (approximately 600 students) but different location - one urban, the other rural. At each site, 12-15 educators volunteered for a 45 minute interview that explores perspectives of rj, training, and current practice. Of these, several volunteered to participate in three interviews and regular observations of their practice over a six-week period. I selected two teachers from each school who had been trained within the past three years, and who represent different grade levels. This allows for depth and breadth of experience (Patton 2002). 
The resulting field notes and transcriptions were coded, and narratives were written. Analysis includes the use of critical, reflective questions from the outset such as: How is rj being defined by this person? How is rj being framed in its implementation? Whose interests are being served? Critical incidents, those "events rendered critical through analysis" (Tripp 1993, 25), are identified. From these, findings emerge that contribute to a more in-depth understanding of the impact of rj in schools and reveal how co-optation of key principles and practices by a punitive approach is possible.

What follows is an overview of the findings, followed by a close examination of the practice of two of the participants to illustrate the contrasting results of similar professional development experiences.

\section{Analysis}

\section{Policy, administrative and educator context}

Overall, the study reveals how the introduction of $\mathrm{rj}$ in a school has varying implications for teacher pedagogy. At both schools, teachers who had engaged in identical or similar professional development experiences were impacted in very different ways. When Clandinin and her colleagues (2006) identify teacher knowledge as a narrative construction composed in each teacher's life and made visible in practice, the variables of each teacher's personal experience are acknowledged as accounting for the different understandings that develop. However, school boards engaging in new initiatives seem to ignore the impact of personal lives on understanding change, and expect that a professional development experience will result in a comprehensive change for all. This was evident in the fact that both school boards represented in the study used 
one-off training sessions with little or no follow-up. Examining how rj is understood by looking at the pedagogy of teachers reveals as much about how schools and school boards operate as it does about the teachers themselves.

In summary, the two school boards in which the teachers' pedagogy is examined had turned to rj initially to reduce suspensions and expulsions and/or to address situations of bullying and harassment. Though there is evidence that each is receptive to a holistic understanding of rj as described above, the details of policy documents and training content reveal it to be situated in a context of control and compliance with a focus on changing inappropriate behaviour. This is most obvious for both in not only the repeated use of the terms victim and offender, and the process allowing for offenders to be held accountable, but also the emphasis on an incident without its context. In one board, the rationale stated for the use of $\mathrm{rj}$ is completely focussed on the youth causing the harm, with no reference given to the needs of the one harmed or the need for building relationships. The other board identifies the needs of the one harmed and the broader community, but effectiveness is articulated as a result of what adults provide for youth in terms of support and expectations, assuming that students must be shaped and moulded by those who know so that they can become contributing citizens as adults. Framing rj as a response to behaviour allows for an explicit legitimating of adult, authoritarian power. While there is a clearly expressed desire to nurture children and youth, a benevolent dictatorship emerges, which Harber and Sakade (2009) state is no less a manipulation for serving the interests of the dominant culture.

This is clearly seen in the comments of the administrator of Pine District School who states she is fully committed to rj and believes it to be significant for changing 
school culture. In reviewing the school's commitment to rj with students at all grade levels, she explains that as adults in the school they are committed to working with students through rj as long as they comply. Referring to the social discipline window (McCold and Wachtel 2003) that is the framework for this board's ${ }^{1}$ implementation of rj, she states:

We want to be in the WITH box because we like kids and believe this is important. I try not to ask, Why? However, if rj doesn't work we move into the TO [punitive] box... we tell you the rules, if you break them, you are reminded. If you still do it, we'll talk more; if you still do it, we'll get all sides; if that doesn't help, we'll need to move to the TO box.

It is obvious from this statement that rules, rather than relationship, continue to dominate even for individuals committed to the implementation of $\mathrm{rj}$, indicating that board policies have far-reaching effects.

Turning now to the expression of rj in teacher perspectives and pedagogy, evidence of the board perspective emerges. What is significant to note, however, is that a few teachers grasp that rj is primarily about building relational cultures and use it to strengthen their practice, despite the board perspective.

Each of the approximately 30 teachers interviewed and observed in both sites indicated that their adoption of rj was not clearly situated in either a discourse of behaviour and management or engaged and productive pedagogies, but was located somewhere on a continuum between the two. In most instances, teachers primarily referred to the impact of rj on behaviour while indicating their desire to be in relationship with students, which is not surprising given the school boards' emphases. In each school,

\footnotetext{
${ }^{1}$ In Ontario, schools are organized into regional groups and called School Boards.
} 
two or three educators reversed this emphasis. In examining this more closely in the participants who agreed to be observed over a six-week period at both schools, several interesting details emerged that are outlined and summarized in Table 1 and in what follows.

Teachers who situated rj within a discourse of engaged or productive pedagogies, when asked to give some background to their decision for becoming a teacher, shared detailed personal experiences they had as children, siblings, or parents, with people they loved who had academic or social-emotional challenges. They articulated a view of the child as being honourable and worthy, regardless of their capacity to be productive either academically or socially. Their role as a teacher was one of support, respect and encouragement not only for their students in particular, but also for all people as they were encountered through the curriculum content. Their focus for the students was on both the present (education to enrich the lives of the students' current experiences) and the future (education to empower them to develop their gifts for future expression). They recognized the constraints of their particular institutional structure (i.e. standardized testing, curriculum expectations, resource allocations, policy expectations, etc.) but looked for ways to work around these constraints within the space they had. For example, Terri $^{2}$ was not daunted by the need to prepare her Grade 6 students for provincial testing, but took the opportunity to develop cooperative activities that encouraged students to assess the quality of their work, which led to less fear in the testing experience. Laura, because of her rj training, celebrated the relational aspect presented, and understood it as

\footnotetext{
${ }^{2}$ All participant, school and school board names are pseudonyms.
} 
permission to set aside time in her Grade 2 daily schedule for class meetings to build community and address concerns.

Those who situated rj within a discourse of behaviour and control did not share personal experience stories of the type related above when describing their reason for becoming teachers. Instead, their stories expressed motivations such as desire to: help students succeed; share their personal strengths and interests with youth; find a job they felt capable of doing. These teachers viewed rj as a practice to be employed apart from their formal teaching assignments as a management tool when students misbehaved, or as a practice employed by administration when faced with the students that teachers had referred to them. They articulated a view of the child as one who had not yet arrived, as one who was valuable if they complied with social norms. Their role was one of guide, manager, director, or expert, with an emphasis on the future of the students and their contribution to society as adults. Within this discourse of behaviour and management, it was not unusual for teachers to dismiss the value of rj, or decline using it if they felt they had effective classroom management skills. Those who struggled with classroom management tentatively attempted to use rj strategies to address behaviour, but were also quick to dismiss them when students didn't respond as training said they would. If they did employ rj, the approach was used primarily with incidents of misbehaviour, and as the facilitator, they tended to maintain control through anecdotal comments that sent messages to students that compliance was the goal.

[Table 1: Restorative Justice within two distinct discourses]

\section{What pedagogy reveals}


The following two cases elaborate on the summary above, and are illustrative of details observed over six weeks of two teachers practice that led to the finding. The teachers presented here are from the same school, have had similar board-sponsored training experiences, teach similar grade levels, and yet, interpret and enact their introduction to rj differently. In Patty's experience, findings reveal how rj, in the context of behaviour and management, appears to get co-opted to reinforce punitive, managerial structures of schooling. In Terri's experience, rj, in the context of engaged and productive pedagogies, nurtures relationship-based cultures. Though details from the other school context in this study differ, similar findings emerged. [Article length limits including details of all participants. For full details see Vaandering (2009).]

\section{Patty}

Patty teaches two Grade 5 extended French classes at Pines Elementary School. After completing a BA in psychology, a Master's degree in Educational Studies, and two years as a substitute French teacher, Patty returned to university to earn her Bachelor of Education. At the time of this study, she had been teaching full-time for two years.

Patty is a confident, well-planned teacher, who uses a variety of approaches. Her approach, she says, comes from her view of the child as being "an inquisitive, curious, growing creature that will have interests, likes, dislikes, [their] own thoughts and ideas, a keen sense of interest in his or her surroundings, very easily influenced and hopefully steered or guided by someone kind and caring." She tries to connect the classroom experience to the child's whole life experience in her attempt to live out Dewey's philosophy that "school is life." Patty finds this difficult to enact. She states: 
Education in this province at this time is also very curriculum driven and testing driven and standardized assessments here, there and everywhere and I as a teacher spend less time I feel on the life stuff than I'd like to.

Patty participated in rj facilitator training a year after the rest of her colleagues, because her position began after the original training. She explains she loved the training, is intrigued by rj and its principles, and understands that $\mathrm{rj}$ is "opposite from the way our whole system works." She situates rj in a discourse of behaviour and control but also alludes to the impact on the role of community. She states:

I'd say [rj practices] are a way of dealing with conflict situations where there's a problem and it's just a way of solving the problem where you get to hear both sides of the story, maybe get a closer version of what really happened and then work through it to a solution that makes everyone accountable, including the teacher.

Her enthusiasm is evident in the fact that shortly after she returned from training, she facilitates a classroom meeting to address a situation where a girl was in tears because someone made fun of her. In her description of the event, it is evident that Patty has grasped that those harmed, those causing harm, and those impacted indirectly should have a voice in resolving issues. However, she has not fully understood the training, which was clear about the importance of creating a safe space for the one who has experienced harm. Counter to what Patty has been taught, she expects the girl to share her story first. This makes the girl more vulnerable, as the one causing harm is then able to refute what has been said. Patty's lack of understanding is also evident when she describes another event requiring intervention: 
When it's serious enough to talk about it, when kids come to me and say something to me, I will haul over the other kid and I'll say, could you repeat that in front of [student A] and then I'll say to the other child, like "what do you think about that?"

In Patty's use of the word haul, and in demanding that students confront each otheragain with the one harmed required to speak first - she exposes her belief that as the adult, she is dominant.

Patty's early interest and efforts in rj further deteriorate, however, when she discusses her initial excitement about rj with colleagues expecting support:

\begin{abstract}
When I came back [from training] I asked some of the teachers that had been trained previously, what they thought about it because I just thought it was great and most of them thought it was great but a little, 'ya so what. We do that anyway... this is part of what we do normally.' Whereas to me, it was new and being new to the school and last year being a first year, brand new teacher...like I just had so many other things to worry about.
\end{abstract}

Immersed in the busyness of everyday teaching, feeling the weight of curriculum expectations and testing, Patty allows her colleagues' responses to sway her from her initial enthusiasm. She sets out intending to be attuned to the emotional, relational needs of the students in the class. This dissipates, and she defaults to an approach that is attentive to instructional detail, transmission of knowledge, and student academic success, but seemingly indifferent to the emotional and relational concerns of her students. This is starkly evident in the following lesson I observed.

In a social studies unit on government and democracy, Patty has divided the class into political parties and for several weeks students have been 'campaigning.' Observing the class on voting day, I identify the political party leaders and watch the significant anxiety 
they are feeling. In brief conversations with each party candidate I discover that Eric feels like puking, Joshua feels like peeing his pants and Michael expresses hurt stating quietly with eyes downcast, “I won’t get any votes."

"Really," I ask. "Why?"

"I don't know I just won’t."

Where Joshua and Eric have peers nearby as they work on the egg painting art activity that occurs at the same time as the voting, Michael sits alone as his party has decided to throw their support behind Eric's party to shift the balance of power away from Joshua's dominant party. There is no campaign party near Michael. He simply sits alone, eyes lowered, shoulders hunched working absentmindedly on an activity while he waits for the class to finish voting. Michael's expectation is correct as his party gets one vote. Though there is a cake Patty has baked to celebrate, there is a subdued, less than a celebratory atmosphere in the class. A brief discussion wraps up the culminating election where a few students indicate that they have learned a lot and Patty states, "All people handled themselves maturely. Great quality of teamwork. Merci.”

Patty's earlier definition of rj as a problem-solving approach seems not to enter her mind in this context of teaching and learning. She does not recognize the relational disruption this learning activity is causing, and takes no time to address the confusing emotions of the students, either as a group, or individually. Where earlier she seemed somewhat attuned to rj addressing the emotional needs of her students, she now states clearly when asked if rj has impact on teaching, "I don't think it affects the way I teach or what I teach or how I teach really. More how I deal with conflict; like ... out on the schoolyard on yard duty."

Examining another conflict incident reveals a further distortion of Patty's initial, yet limited understanding of $\mathrm{rj}$. In this situation students are practicing gymnastic 
routines during gym class. She asks a student to sit off to the side, as he is repeatedly offtask and disrupting his group. Later, I ask Patty if rj can contribute to situations like this:

It doesn't. That's when you need to be firm with the kid and say, "What you've done is unacceptable. I don't want to talk about it. You know yourself that it is ridiculous". ... No one's been hurt by this behaviour...to me [rj is] just something that you use ... as a strategy for bigger problems. This is between the boy and me and I want him to stop behaving like a fool and he knows it.

Where she once felt rj was a means for problem solving where the teacher too was accountable, in this incident she does not recognize that the student's behaviour has had an impact on others, and no longer sees its applicability for her relationship with the students. Along with this, Patty herself seems not to notice her shift in perspective and practice, as throughout the research time period she continues to articulate that she is a strong proponent of rj practices in their school.

\section{$* * * * * * * * * *$}

In examining the progression of Patty's engagement with rj it becomes evident that initial enthusiasm and early understanding gives way to rj endorsing hierarchical, authoritarian practice. Her story shows she is constrained by mediating aspects of [institutional] culture (Chase 2005) to the point where rj situated in a context of behaviour and management actually reinforces an agenda of control and compliance. Several things contribute to this. First, as a beginning teacher, Patty is conscious of her need to comply with board policy, and though she feels controlled and limited by this, sensing that her ability to make informed educational decisions is not trusted, she is uncertain as to how to interpret the board-endorsed rj training that she understands as 
"totally different than how the system works." Second, seeking support and reassurance for her capacity to teach, she depends on her peers for approval and direction. Her colleagues' response to her initial enthusiasm confuses her and sends her a message that $\mathrm{rj}$ is not a radical systemic change, but already part of what is done at the school. As a new teacher, perhaps fearing that continued excitement could indicate to others that she is not operating within what is considered the norm, or perhaps considering herself to be an effective teacher already as students were well-behaved in her class, her colleagues' responses signal to her that she too must be using rj. Finally, her view of the child as "very easily influenced" and in need of "kind and caring guidance" places her in a position of control, as students cannot be trusted to know what is best for them.

Patty's practice reveals exactly what Thorsborne and Vinegard (2006) indicate should not occur - that rj practices "cannot be viewed as isolated interventions or tools that a school uses only when required" (11). Though Patty initially appears to grasp that comprehensive change is required, what her narrative clearly indicates is that change cannot occur without a safe space where critical discourse is encouraged, thereby enabling the interrogation of both the impact and effect of hierarchical power structures in schools. There must be an increase in conscious awareness of how institutional bureaucracies and social norms have considerable influence on the people within a school, in terms of their capacity to impede or nurture a commitment to building humanizing relationships.

Terri 
Terri has been teaching grades five to seven at Pines Elementary School for ten years. At the time of the study, she was teaching Grade Six. Prior to her employment at the school, she held positions in the areas of adult and family literacy, as well as life skills programs for youth who dropped out of schools. Terri enjoys her current position stating, "I think this is where I belong." She identifies herself as a reflective, caring teacher who is drawn to students from lower socio-economic environments with academic needs because she sees herself as a child in them. "I'm those children in many ways so I think I hear them and I understand when they struggle to learn ... I try to support them and help them blossom." Thus, Terri is intent on conveying to her students that they are valued. From this vantage point, in reflecting on her one-day rj training provided by the school board, Terri states, "[rj is] just a name ... I think restorative practice is who I am anyway." When asked to elaborate, Terri explains,

I do believe that my role is to listen to what these children are concerned about, whether they're mine in my classroom or they're in the hall and to ensure they've each had a voice and that we somehow settle the difficulties, the hurt feelings, that they walk away feeling restored, that they had a chance to be heard. What I like best about [rj] is the focus is not always on the bad behaviour, the poor choices but that the focus is on the kid that got hurt, whether it was physically or emotionally. I like that because I think that as teachers, we are in charge and we do tend to always go to the kid that made the poor choice and that's where we spend all our time and energy. I like the idea of giving more time and attention to the injured party. I always try to keep that in my head ... I think [rj] reminds teachers that we are not all powerful, that children have power too and they should be given their power ... they have a right to express themselves. But I think as teachers, part of our tendency is to [convey] 'I'm right, you're wrong; I'm big, you're little; I'm smart, you're dumb." 
These comments follow Terri's definition of rj as "a process for resolution of issues that is fair and gives everyone a voice." As she reflects, she begins to question what rj really is.

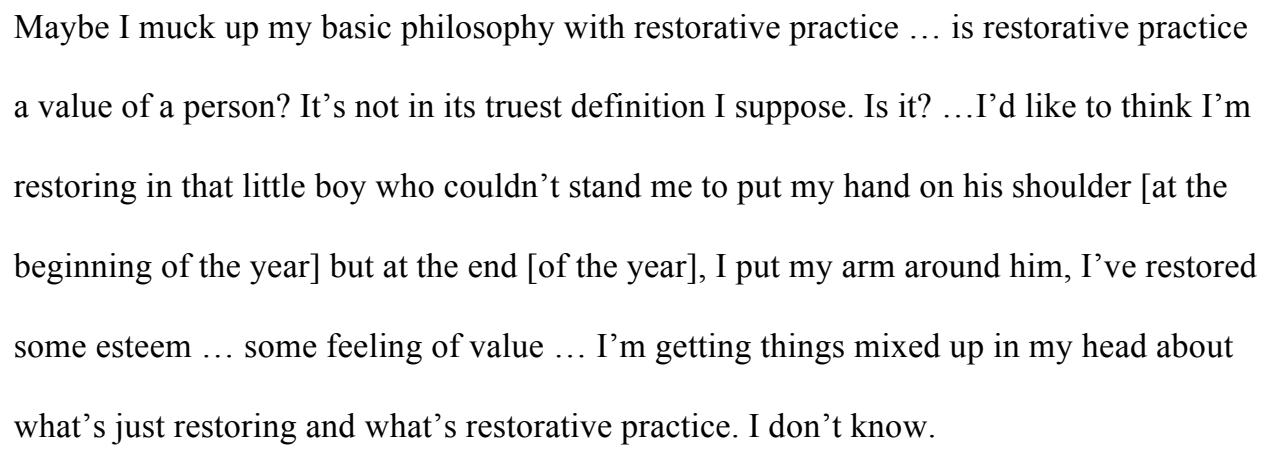

Though Terri is puzzled by what rj is, she is confident in herself, her view of the child, her role, and her purpose for teaching. In spite of the emphasis on rj for impacting student behaviour in the training, it appears to serve as a mirror that reflects back to Terri what she sees as her own pedagogical practice. This practice, which I observed over the six weeks I was with her, is infused in every way with her intent to value her students highly and unconditionally, seeking their well-being, and encouraging them to make decisions as active members of the class community. Consistently and purposefully, Terri welcomes each person warmly regardless of the time they arrive, gives reasons for any request she has of students ("if you'd turn this way, Paul, you'd be able to get the details"), praises and celebrates their personality and gifts ("That's a really mature way of connecting ideas, Sue"), invites them to share concerns and questions ("I haven't heard this before ... you're really frustrated by this"), gives them a voice and choice in selecting activities and groups, and allows them to participate in assessment practices. In curriculum content, Terri highlights relationship and community at every opportunity regardless of whether it is math, social studies or language arts. When I point this out to her she indicates that this 
is not an explicit plan on her part, revealing just how integral this perspective is to her identity. When students are hurt or cause harm to others she responds as soon as possible and, without judgement, she provides an opportunity for students to find ways to repair harm and rebuild community through dialogue.

In some ways it appears rj training has done little to change Terri's practice. But the following experience, Terri explains, would not have occurred without the training she received or the school's commitment to rj. When Greg physically harms a peer during class and is required to take some time out, the majority of the students express to Terri their frustration with him as he has been sexually harassing many of them. Immediately, Terri draws the class into a circle and invites each to share their concerns, assuring the students that the meeting is to find ways to support each of them as well as Greg. As details emerge, Terri calls the administrator to join them, who reiterates her intention to support each of them. Terri thanks each of them for their honesty and assures them that all of their concerns will be addressed as the situation is examined more closely. The sense of community and relationship present in the class is foregrounded when a student provides the final comment: "I just want everyone to know that I've known Greg since he was little and really he is a good guy, he just got into some trouble now."

A week later, after Greg's needs are addressed with his parents and a plan is implemented that includes the school, family, and counselling, he is invited back to class. Reintegration is of utmost concern to Terri, so she facilitates a restorative circle where Greg had a chance to express his thoughts and feelings about what happened and the students had opportunity to share their concerns. Through tears Greg apologized and then 
listened to his peers tell him briefly how what he did just didn't feel right to them, scared them, made them feel disgusted and sick to their stomach. Providing concluding encouragement for the circle of students, Terri assures Greg he is an important part of the class, and reinforces that when harm is done they need to work together to find the reasons for it and then ways to repair the harm done. Terri and the administrator realize Greg will require supervision and support, and that it is possible he will reoffend. They commit to protecting the class and digging deeper into Greg's needs if this occurs.

Terri's approach is well received by her students who are often considered to be less academically capable and involved in conflict situations more frequently because they are not in the French immersion program. One student, Paul, tells me he is new to the school this year, coming from a school where he had been in a special class for students with behavioural issues. He sums up the impact Terri has on the class when I ask him why he is not in a similar class at this school. "I'm doing fine here," he states, "because Ms. Tanner [Terri] cares about me, about us."

\section{$* * * * * * * * * * * * * * * * *$}

In examining the impact of rj on Terri's pedagogy it becomes evident that rj situated in the discourse of engaged and productive pedagogies, results in deeper, relational classroom cultures. When practice is rooted in a view that students are to be valued as worthy human beings with insight, capacity for self-expression and for making decisions for their own well-being, control and behaviour take a back seat as pedagogy becomes proactive and facilitates learning and building relationships. 
Terri embodies an engaged pedagogy (hooks 1994) that sends students messages of belonging through an emphasis on well-being, connecting life to learning, valuing student expression, empowering students and teachers, and transforming the curriculum so that it does not reflect biases or reinforce systems of domination (13-22). She also exemplifies the key elements of productive pedagogies: intellectual quality, connectedness, supportive classroom environment, and valuing and working with difference (Lingard, et al. 2003).

Terri's pedagogy was set in place before she had ever heard of rj. Because she believes "rj is who I am anyways," training and participating in this research study has not changed what she does, but only confirms what she is committed to doing as a teacher. It reminds her of the potential for abuse of power by educators when they believe their value is rooted in their ability to control others. By explicitly insisting that rj not be restricted to repairing harm but broadened to encompass the well-being of all, and the building and affirming of relationships, Terri strains against mediating aspects of institutional culture (Chase 2005) and demonstrates that rj is really a commitment to humanization - the support of people in "their ontological vocation of becoming more fully human" (Freire 2005, 74). It is from this broader perspective that rj, with its emphasis on dialogue, contributes to what Freire identifies as "liberation [as] praxis - the action and reflection of people upon their world in order to transform it" (79). This is a proactive stance that demonstrates how rj situated within engaged and productive pedagogies nurtures a deeper, relationship-based classroom culture.

\section{Discussion:}


In the effort to transform schools from operating as rule-based institutions to living out of a relationship-based foundation through rj principles and practices, the highly resistant, hierarchical, authoritarian system that expects to instil attitudes of obedience and conformity (Green 1990), must be confronted. Such systemic change requires of its participants a conscientization (Freire 2005) of the structures that currently constrain them. This study indicates that little attention is given to these structural elements as policy-makers and educators attempt to insert rj into existing structures. The failure to address the structural and institutional influences acting on school participants and rj, reduces rj to a decontextualized skill-building exercise committed to further controlling behaviour or producing empathic social relations. There is little awareness of the need to reflect deeply on how personal and professional actions and beliefs are enmeshed in the broader systemic social and institutional contexts in which power relations are negotiated. To increase awareness of their own contribution to the proliferation of hegemonic practices that sit at the root of individualistic, rule-based, institutional cultures, Lingard, et al. (2003), in their work on the development of productive pedagogies as a model for classroom practice, identify that for systems to change, teachers' practice must be a central focus. This is not to absolve the system of factors that impact teaching, but serves instead to highlight the sociological connection between teaching and learning.

In this light, as Terri demonstrates through her practice, teachers are able to strain against the mitigating structures within which they work. When these structures are highlighted, insight is provided for more effective implementation of educational practices that seek to honour and empower youth. In a similar way, this study also strains 
against hegemonic institutional practice by examining pedagogy, a key site of interaction in schooling rather than behaviour.

Implications emerge for effective implementation in schools that include the need for:

- A broader conceptualization of rj that more clearly defines its underlying philosophy and principles;

- Critical reflection by policy makers and educators on personal core values and how they align with principles of rj;

- Critical examination of current training and espoused theories to identify reinforcement of power relations leading to punitive practice;

- More comprehensive resources that allow for and encourage the development of supports within school contexts beyond an initial introduction to rj;

- Development of pedagogy where learning, not control, is the priority (Ireson, Mortimor and Hallam 1999). This will occur when teachers reflect critically and assess (a) how they engage with students and encourage them to become more fully human, active community participants, and (b) how they are causing students harm or alienating them. In this way educators take on a leadership role as 'transformative intellectuals' (Giroux 1988) within the systems of which they are a part.

\section{Looking ahead}

In the ongoing pursuit for creating nurturing, safe, and relational school cultures, integrating rj principles and practice holds potential if understood outside the context of 
behaviour and control. However, by listening to and observing teachers, this study underscores the challenge of creating such school cultures in an institutional context designed to instil attitudes of obedience and conformity. Setting the challenge within the context of engaged and productive pedagogy is a beginning step that uncovers the need for educators, administrators, and policy makers to become conscious of their view of humanity, the underlying motives of the educational institution, and the impact they have as adults in their relationships with students and colleagues. By removing rj from a discourse of behaviour, this article deepens the discussion to include the habitus -- the taken-for-granted structures and systems -- which McClutsky et al. (2008) suggest is the central challenge facing rj in schools (413). However, as pedagogy has rarely been included in empirical studies examining $\mathrm{rj}$, more research will be required to solidify the findings presented in this article and to extend the dialogue.

Acknowledgements: The author wishes to acknowledge the support of the Social Sciences and Humanities Research Council of Canada and the Ontario Graduate Scholarship for this research. 


\section{References:}

Amstutz, L., and J. Mullet. 2005. The Little Book of Restorative Discipline For Schools. Pennsylvania: Good Books.

Bianchi, H. 1994. Justice as Sanctuary. Bloomington, Indiana: Indiana University Press. Bickmore, K. 2011. "Location, Location, Location: Restorative (Educative) Practices in Classrooms.” Paper presented at the ESRC 'Restorative Approaches to Conflict in Schools' Seminar \#4, University of Edinburgh.

Chase, S. 2005. “Narrative Inquiry: Multiple Lenses, Approaches, Voices.” In Handbook of Qualitative Research, edited by N. Denzin, and Y. Lincoln. Thousand Oaks: Sage Publications.

Clandinin, D. J., J. Huber, H. Marilyn, M.S. Murphy, A. M. Orr, M. Pearce, et al. 2006. Composing Diverse Identities. New York: Routledge.

Denzin, N. K., and Y. S. Lincoln, eds. 2005. The SAGE Handbook of Qualitative Research. Thousand Oaks: Sage.

Freire, P. 2005. Pedagogy of the Oppressed (30th ed.). New York: Continuum. Green, A. 1990. Education and State Formation. London: Macmillan.

Hadley, M. ed. 2001. The Spiritual Roots of Restorative Justice. Albany, New York: State University of New York Press.

Harber, C., and N. Sakade. 2009. "Schooling for Violence and Peace: How Does Peace Education Differ from 'Normal' schooling?' Journal of Peace Education 6 (2): 171-187.

Hayes, D., M. Mills, P. Christie, and B. Lingard. 2006. Teachers and Schooling Making a Difference: Productive Pedagogies, Assessment and Performance. Sydney, AU: 
Allen and Unwin.

hooks, b. 2003. Teaching Community: A Pedagogy of Hope. New York: Routledge. hooks, b. 1994. Teaching to Transgress: Education as the Practice of Freedom. New York: Routledge.

Hopkins, B. 2004. Just Schools: A Whole School Approach to Restorative Justice. London: Jessica Kingsley Publishers.

Ireson, J., P. Mortimore, and S. Hallam, 1999. "The Common Strands of Pedagogy and their Implications." In Understanding Pedagogy and Its Impact on Learning, edited by P. Mortimore, 212-232. Thousand Oaks: Paul Chapman Publishing.

Jones, T. S. 2004. "Conflict Resolution Education: The Field, the Findings, and the Future." Conflict Resolution Quarterly 22(1-2): 233-267.

Kincheloe, J. L., and P. McLaren, 2000. "Rethinking Critical Theory and Qualitative Research.” In Handbook of Qualitative Research edited by N. Denzin, and Y. Lincoln. Thousand Oaks: Sage.

Lather, P. 1986. "Issues of Validity in Openly Ideological Research: Between a Rock and a Soft Place." Interchange 17 (4): 63-84.

Lederach, J. P. 2003. The Little Book of Conflict Transformation. Pennsylvania: Good Books.

Lindstrom, S. R. 2007. "Review of School Violence Intervention Best Practices.” Context: The Journal Recognizing Student Health Professionals Engaged In Their Communities 1 (Fall).

Lingard, B., D. Hayes, and M. Mills. 2003. "Teachers and Productive Pedagogies: Contextualizing, Conceptualizing, Utilizing.” Pedagogy, Culture and Society 11 
(3): 399-424.

Lockhart, A., and L. Zammit. 2005. Restorative Justice: Transforming Society. Toronto: Inclusion Press.

McCluskey, G., G. Lloyd, J. Kane, S. Riddell, J. Stead, and E. Weedon, 2008. “Can Restorative Practices in Schools Make a Difference?” Educational Review 60 (4): 405-417.

McCold, P. and T. Wachtel. 2003. "In Pursuit of Paradigm: A Theory of Restorative Justice.” Restorative Practices E-Forum. Retrieved from http://www.realjustice.org/library/paradigm.html

Morris, R. 1998. “Why Transformative Justice?” Paper presented at the ICCPPC World Congress, Mexico City.

Morrison, B. 2005. "Building Safe and Healthy School Communities: Restorative Justice and Responsive Regulation.” International Institute for Restorative Practices 6th International Conference.

Morrison, B. 2007. Restoring Safe School Communities. Sydney: Federation Press.

Patton, M. Q. 2002. Qualitative Research and Evaluation Methods. Washington: Sage Publications.

Pinheiro, P. 2006. World Report On Violence Against Children. Geneva: United Nations. Porter, A. 2007. “Restorative Practices In Schools: Research Reveals Power of Restorative Approach, Part 1.” Restorative Practices E-Forum, 2.

Porter, A. 2007. “Restorative Practices In Schools: Research Reveals Power of Restorative Approach, Part 2.” Restorative Practices E-Forum, 3.

Pranis, K. 2007. “Restorative Values.” In Handbook of Restorative Justice, edited by G. 
Johnstone, and D. Van Ness, 59-74. Devon: Willan Publishing.

Pranis, K., B. Stuart, M. Wedge, 2003. Peacemaking Circles: From Crime To

Community. Minnesota: Living Justice Press.

Reistenberg, N. 2011. “Seeding Restorative Justice Measures In Minnesota: Challenging Opportunities." Paper presented at the ESRC 'Restorative Approaches to Conflict in Schools' Seminar \#4, Scotland.

Thorsborne, M., and D. Vinegrad, 2006. Restorative Practices in Schools: Rethinking

Behaviour Management. Queensland: Inyahead Press.

Toews, B., and H. Zehr, 2003. "Ways of Knowing for a Restorative Worldview.” In Restorative justice in context, edited by E. G. M. Weitekamp, and H-J. Kerner, 257-271. Devon: Willan Publishing.

Tripp, D. 1993. Critical Incidents in Teaching: Developing Professional Judgement. London: Routledge.

Vaandering, D. 2009. Towards effective implementation and sustainability of restorative justice in Ontario public schools: A critical case study. Ph. D. Unpublished dissertation, University of Western Ontario, London.

Vaandering, D. 2011. A faithful compass: Rethinking the term restorative justice to find clarity. Contemporary Justice Review, 14(3), 307-328.

doi:10.1080/10282580.2011.589668

Watkins, C., and P. Mortimore. 1999. “Pedagogy: What Do We Know?” In Understanding Pedagogy and its Impact on Learning, edited by P. Mortimore, 119. Thousand Oaks: Paul Chapman Publishing.

Zehr, H. 2005. Changing Lenses: A New Focus for Crime and Justice (3rd ed.). 
Restorative Justice: What pedagogy reveals

Waterloo: Herald Press. 